\title{
3D-Cephalometric Analysis based on afferent sense
}

\author{
Prof. Dr. Gerhard Polzar (KKU), \\ Dipl.-Ing., Dipl. Inform. Frank Hornung
}

The new benchmarks to determine the human skull precisely in 3D for the investigation of anatomic symmetry and asymmetry to verify the sagittal midline plane reference.

\section{Keywords}

3D analysis, CBCT, DVT, midsagittal plane, facial symmetry, orthognathic surgery, skull analysis, craniofacial asymmetry, cephalometry, FRS, craniofacial analysis, CranioPlan ${ }^{\circledR}$, CranioSphere ${ }^{\circledR}$, cranial landmarks, occlusal plane

\section{Background}

The Achilles heel of all systems that measure the human body's anatomy in 3D and especially the cranium, is the lack of a method to establish a reliable and reproducible axiomatic landmark from which it is possible to determine the regions of interest, such as the occlusal plane or the symmetry or asymmetry of the craniomandibulary complex. Each method has its own definition in the fields of view and its own abstract which is not really sufficient to give general advice to the individual or to be matched with other methods. In all fields of research, be it medicine, chemistry etc. there is an "absolute zero", such as temperature, height, weight, blood pressure etc but this does not exist in terms of human symmetry or asymmetry and thus we lack reliable research because there is a different relative point of origin for everyone, lacking an absolute reference point to rely on.

A new idea to create more reproducible stability from a geometric point of view is, to take the most important afferent senses and their point of entrance as the basic points of reference. It is a compelling necessity of evolution to be strong enough to survive and adapt and these incoming sense-points have to be at the most stable and most evidently calibrated position. Constitutive to this idea it is possible to create new, axiomatic landmarks in the area of human skull analysis.

\section{Hypothesis}

If you want to change your position in your environment, if one is an animal or human but not a plant, evolution forces you to adapt to the best orientation with regards to where you are, as otherwise you will be disorientated and will be eliminated from the process of evolution. This is the basic nature of animals and humans and divides the fauna from the flora. Thus, plants have no decision over active movement. This makes animals develop nerve systems with afferent paths respond to stimuli, such as heat, eyesight, noise or gravity. The brain gathers all of this information together in an active manner to prepare the body for active positionchange of the individual to ensure survival and enhance evolution.

This means that if the afferent systems are not calibrated precisely the individual or the species would be at a disadvantage in the process of evolution and unable to reproduce. Based on that fact, it is a logical process to exclusively orientate any anatomical measurements for symmetry and asymmetry around the incoming senses. On the other hand, one can assume that if the incoming senses are not calibrated precisely, the action and reaction of the individual will be connected to the afferent misinformation and the individual will then act only on the misleading afferent information, and even this moving process will only enhance the organs in this specific way and cause asymmetry. As a result of this misleading information, the muscles and the skeletal construction will literally be formed in this manner and may result in asymmetrical growth of the skeleton. All of this is determined by the rule that form follows function, in addition to the function following the afferent information the body is given as orientation. Combined with the phylogenetic information of the species it will produce the individual appearance and growth

Benchmarking all of this afferent information, research has revealed that most of this information comes from the eyesight or the visual sense. The visual sense relays the majority of input-information to the brain. Only a view left for the auricular sense and the equilibration and a minor afferent information data are left for sensation, temperature and sense of smell and taste. This points out that if you want to emphasize the best and 
the most accurate landmarks you should follow the eyesight as the peak sense for orientation.

However, this is not really correct at all; if you benchmark the afferent senses on the basis of their loss, you will come to a very different important conclusion. For example, one can live without eyesight, you are blind but the other senses will help to compensate this. You can live without hearing, as vision and the tactile sense will compensate your deafness as well. The other minor senses will be compensated by experience, for example, if you see a flame you will realize that it is hot as it will burn your skin and even if you cannot feel it you will see its results on your skin. The only sense which has no compensation is the equilibration which gives you every important piece of information of yourself, and your relation to Earth's gravity. Without the sense of equilibration, you will be in a vegetative state, which means that you are really not able to survive properly. The loss of equilibration will make you dizzy, cause vertigo and nausea and you are no more prepared for active movement in an area surrounded by gravity.

Based on these ideas, we can figure out that the primary afferent sense is equilibration followed by the visual sense.

\section{Method}

\section{A: CranioPlan ${ }^{\circledR}$}

Evolution has caused that human primary senses, like vision, equilibration and auditory senses are calibrated with utmost precision in order to allow reliable orientation in the environment. The idea of the CranioPlan ${ }^{\circledR}$

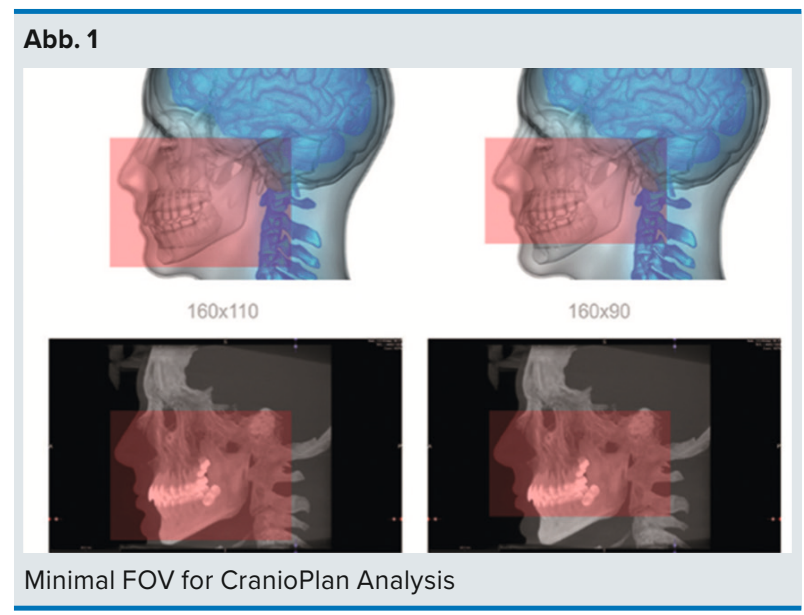

Analysis is, to give exact specified landmarks in the human skull derived from a reference plane. This plane will be taken as a reference for the calibration of any medical or dental therapeutic procedure. The CranioPlan ${ }^{\circledR}$-Analysis was first invented and published by Hornung F, Polzar G in J Compr Dentof Orthod + Orthop (COO) ${ }^{1}$ and Polzar et al. ${ }^{2}$ The theoretical background to this method was described by Polzar G, Süss $\mathrm{JT}$ in the same journal ${ }^{3}$ and the basics to this approach to cranial analysis have been described in 2012 by Polzar in one of the first books on aligner orthodontics. ${ }^{4}$

The unique and new aspect of this method is that it is only determined by the reference of landmarks defined by the primary points of entry of senses penetrating into the human system such as vision, gravity and the auditory sense. Connecting these landmarks, we get the CranioPlane and derived from that, the CranialPoint as the center of consideration and the base plane, as the original basis for anatomic measurements of the analysis of a patient's body.

The materials needed are CBCT with a FOV of $160 \mathrm{~mm}$ $\times 110 \mathrm{~mm}$, but not less than $160 \mathrm{~mm} \times 90 \mathrm{~mm}$. For this $X$-ray DICOM Data set there is no high resolution modus necessary which means, we can minimize the $\mathrm{X}$-ray exposure. However, the CBCT machine itself should be calibrated to give the measurements better accuracy (Image 1). Starting with the analysis, it is necessary to mark the following anatomical structures in the DICOMData-Set: the incus of the right and left side $(\mathrm{O} 1, \mathrm{O} 2)$ (Image 2), and the most anterior point of the corneal curvature of the right and the left eye (A1, A2) (Image 3).

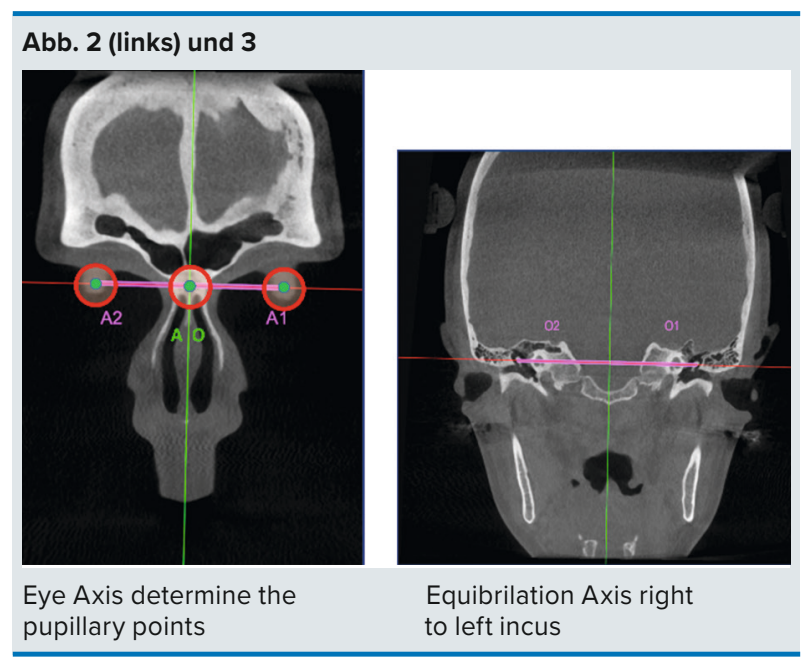


At first, the axis is created between the ear-bones, the right and the left incus, which is the distance of point $\mathrm{O} 1$ and $\mathrm{O} 2$ as the center of the incus on the left and the right side. The other axis is created from $A 1$ to $A 2$. The interesting fact is, that in most cases the ear axis and the eye axis are parallel to each other. Connecting $\mathrm{O} 1$ to $\mathrm{A} 1$ and $\mathrm{O} 2$ to $\mathrm{A} 2$ will construct a trapezoid cranial plane (Image 4, 5).

In an ideal case, this is totally symmetric because this is the most equilibrated aspect of the human body as it is forced to be so. This has been termed the Cranial Plane, and is the starting point for all other ideas and the base for the CranioPlan ${ }^{\circledR}$ analysis.

Creating the geometric center of this now existing trapezoid figure results in the Cranial Axis Point (Image $6,7)$. This schematic procedure is shown in Image 8

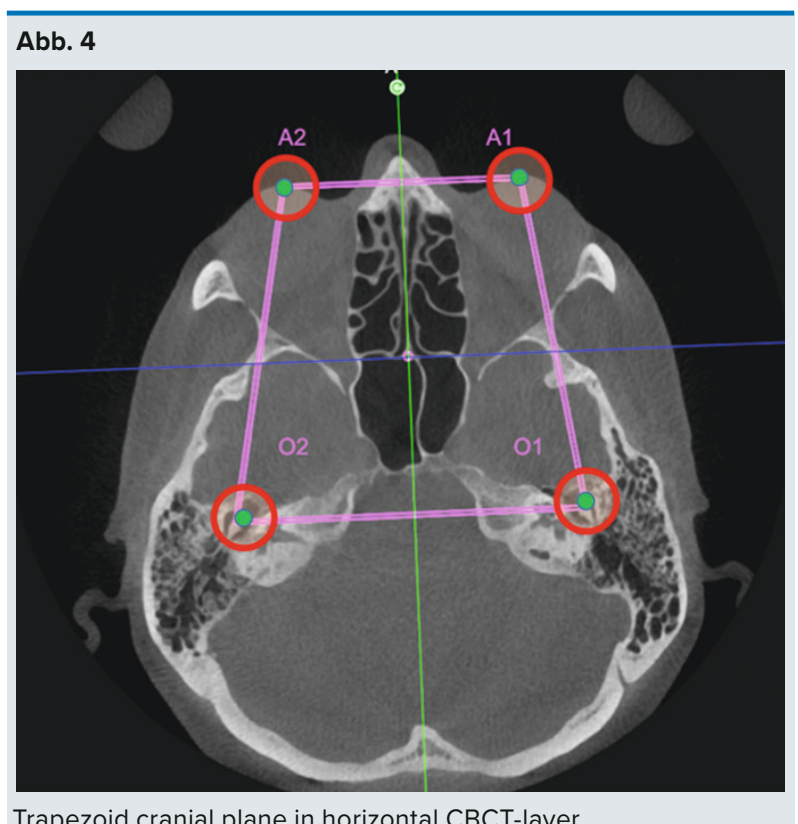

Trapezoid cranial plane in horizontal CBCT-layer

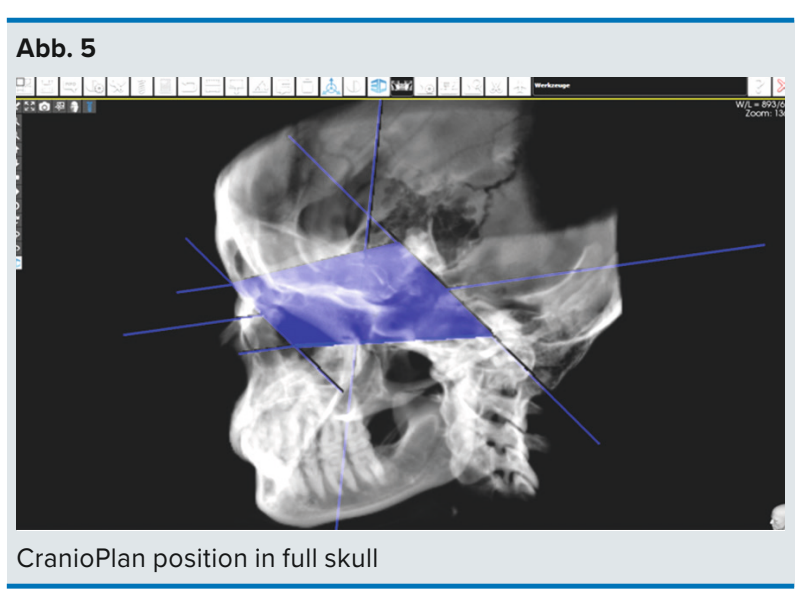

and inserted in the DICOM-Data-Set of the CBCT in Image 5.

In medicine for anatomic orientation the Cartesian coordinate system is used and the vectors define the planes and axis as following: cranio-caudal for the coronal $(X Z)$ - sagittal (YZ) plane-intersection, the vertical axis $(Z)$ and dorso-ventral for the sagittal- horizontal (XY) plane-intersection, the sagittal- or midline axis(Y) and in the center it is called median plane or mid-sagittal
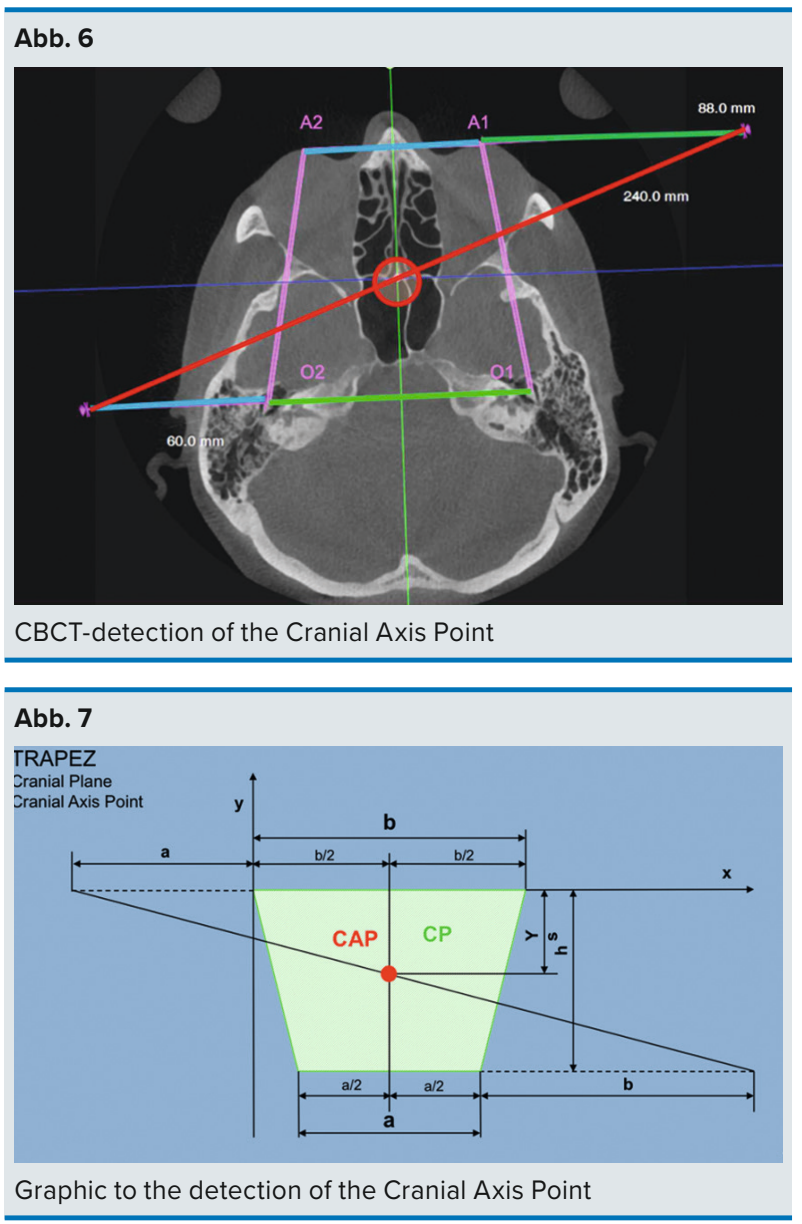

Graphic to the detection of the Cranial Axis Point

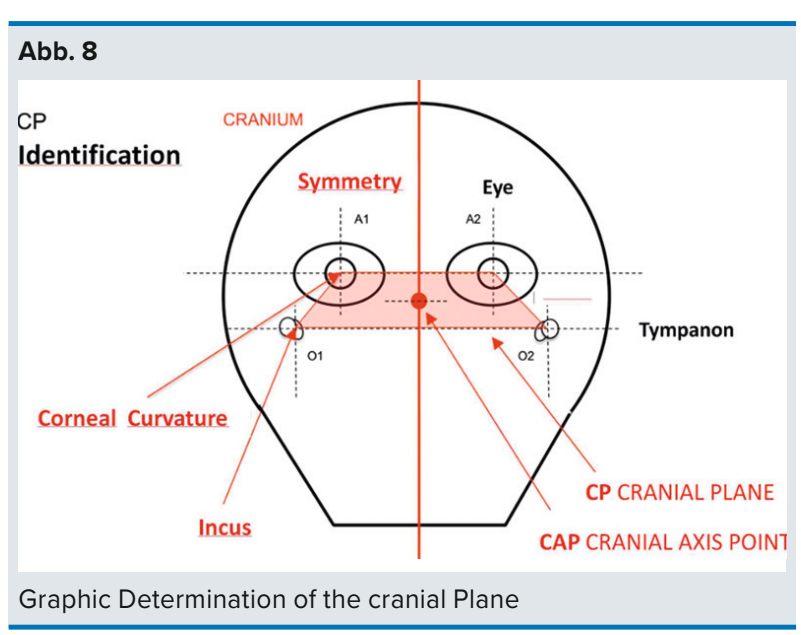


plane and for the horizontal/transversal view from left to right for the called transversal- coronal plane-intersection, the coronal axis (X) (Image 9).

The only problem in this way of view occurs because we have no point zero from where we can start on and match the coordinate system with the anatomy of the human body. Without the point zero and without an exact calibration of the $X, Y$ and Z-Axis as important vectors we lose the orientation for defined scientific measurements especially while investigating on symmetry- or asymmetry studies. Within this new method of CranioPlan ( ) we can now verify and individually figure out from where the considerations have their origin. The axiomatic origin has been determined and is ready for all further anatomic measurements to provide upcoming scientific studies with proof and a solid foundation.
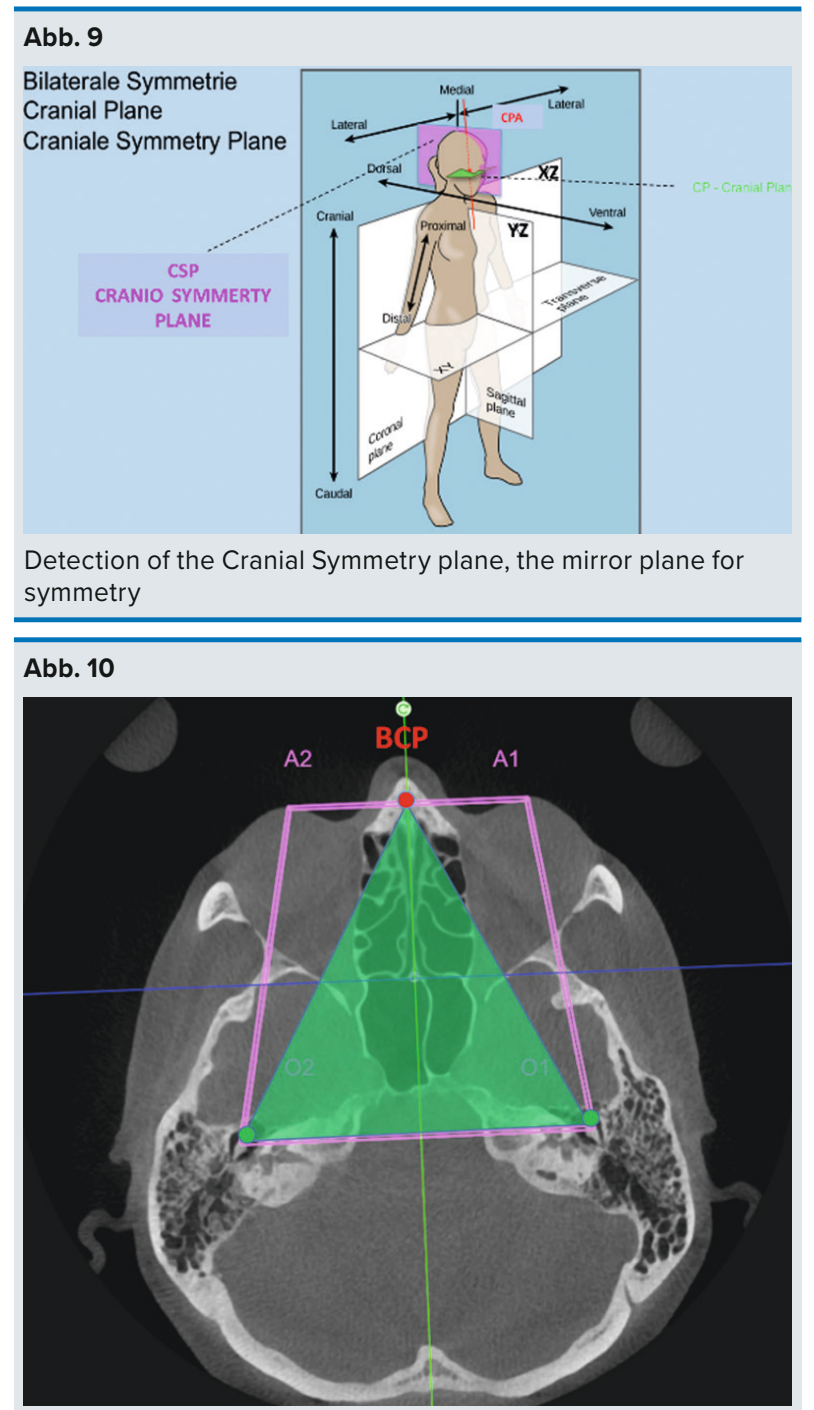

Triangle reduced minimal Cranioplan
The effect of evolution and our own investigations have shown that the number one sense as described above is the equilibration sense and for a precisely fine correction or the first redundant the visual sense is followed as number two. Based on that idea we assume that the baseline between $\mathrm{O} 1$ and $\mathrm{O} 2$ is the best convenient and stabile starting point for all further measurements. Assuming that the point zero $(01-02,1 / 2=Z$-Point $=Z P)$ is defined as the essential centre point between the 01 $\mathrm{O} 2$ baseline, we only need the third point to calibrate the coordinate system in anterior-posterior direction along the XZ-vector.

In order to minimize casually occurring deviations failures of the point $\mathrm{A} 1$ or $\mathrm{A} 2$, we can minimize this discrepancy by constructing a new geometric figure triangle constructed between 01,02 , and A1/2 (Image 10) and position the median line to point $A 1 / 2$. The point $A 1 / 2$ is the bipupillar center point and so called BCP. It might be identical to 2D cephalometric Landmark $\mathrm{N}=$ Nasion, but the Nasion is defined on bone structures and therefore also could differ from the bipupillar midline center.

The point zero ZP is the starting point, or the axiom, for all further scientific or clinical research related to symmetry and asymmetry. It is absolutely vital to give all related studies certainty and accuracy. Based on the midpoint of the landmarks of the two auricular bones, the right and the left incus and the middle of the bipupillar morphometric points we created a sophisticated real craniofacial midline which only is stabilized on the input of afferent senses as the most calibrated part of the human skull. The Axis through this midsagittal plane is defined as the Cranio-Symetrie-Axis, CSA (Image 11,12).

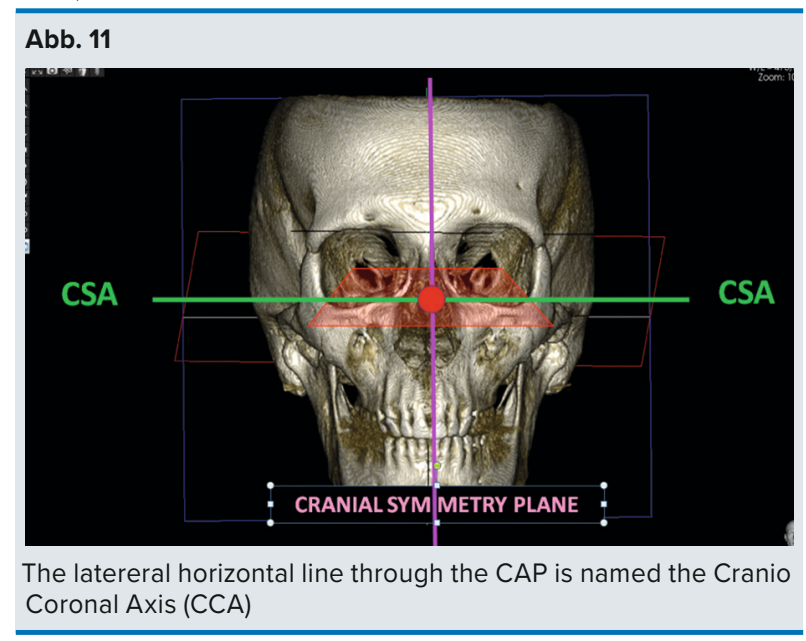


The Axis through the coronal frontal plane is defined as the Cranio-Coronal-Axis, CCA (Image 13) and the axis of the Cranial-Plane is called Cranial-Plane-Axis, CPA (Image 14).

Based on this described model, now we have the Point Zero $(\mathrm{ZP})$ in the first dimension and the triangle called Cranial Base Plane (CBP). For further orientation in three dimension, we need to define a third stable landmark to get into real 3D-Diagnosis. Due to this necessity we established Craniosphere ${ }^{\circledR}$.
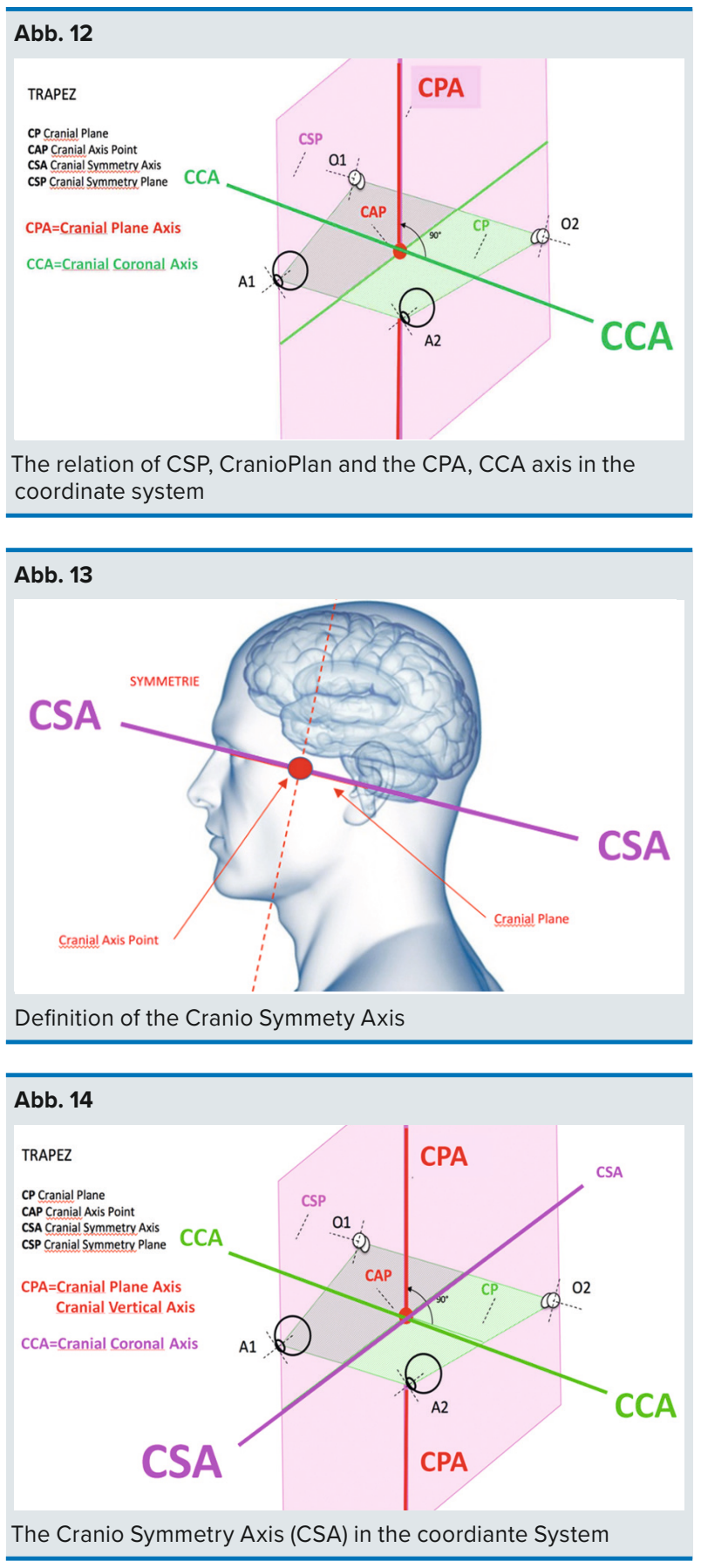

\section{B: Craniosphere ${ }^{\circledR}$}

With the Method of CranioPlan ${ }^{\circledR}$ we are able to describe every point of the human skull, but we are not able to define relationships of specified anatomic skull-structures and the relationship to each other. So we need to find an outer third point, not related to the above described centered coordinate system.

The idea was, what else could give us a stable and solid landmark in the human skull, and even perhaps that it might not be related to the fact of sense stability? So the question was, what could that be and how to find this stable third point to create our cranial sphere. Fortunately, the idea came to us. It must be anything which is forced to be in the center otherwise it would hurt the anatomic structure. And we figured it out! It is the entrance of the nerve-system of the human body into the brain. The entrance of the spinal nerve bundle connected to the lower brain part, the medulla oblongata, is the secret. If it is not centered, every movement of the
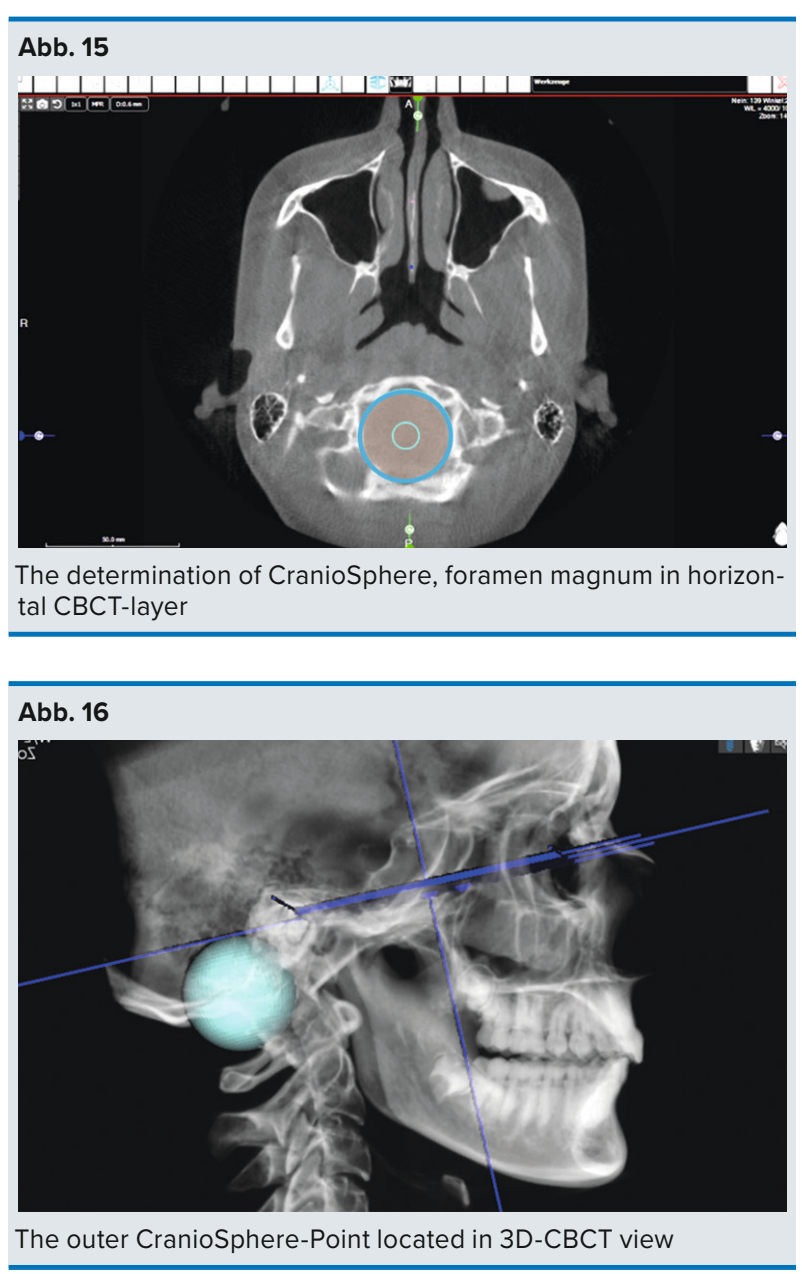
head to the right or left side would squeeze the skullpenetrating nerves. Assuming that fact, we positioned a circle to the edge of the nerve-penetration opening, called foramen magnum (Image 15) and formed a sphere with the diameter of the foramen magnum (Image 16).

Now we let this sphere tangential touch the median vector through the middle of the base plane triangle along the Bipupillar Center Point, BCP and the Point Zero, ZP (Image 17, 18).

Then we doubled the distance line a (BCP-ZP-line) called line $b$ and built an angle back along the median plane touching the foramen magnum sphere tangential at its caudal point (Image 19). The side length of this tangent called line $c$ is the sum of the length $a$ and $b$. The interesting fact of this construction is, that now we can precisely determine the interincisal point to be located at the anterior end of line c (Image 20).

This construction is very helpful for any therapeutic planning in prosthetic dentistry to position the anteri-

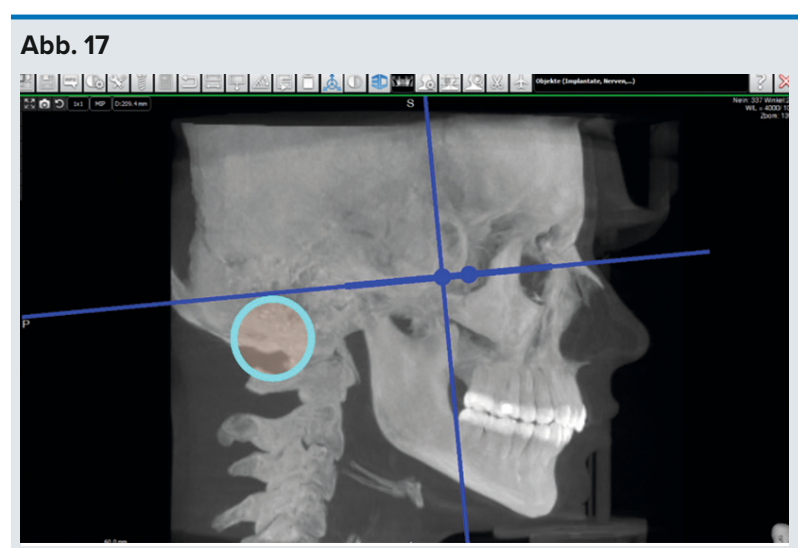

Relation of CranioSphere, CranioPlane and CranialAxis in cephalometric sagittal view

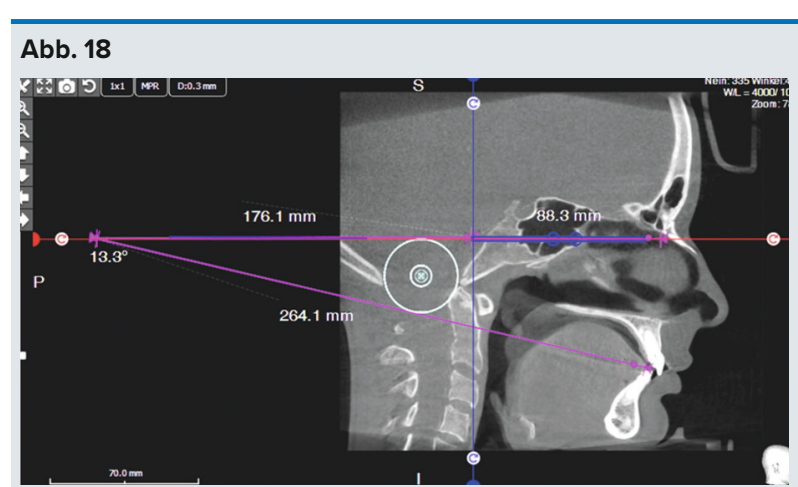

The reconstruction and proof of the occlusal plane and incisal point by CranioPlan and Craniosphere or teeth for full denture reconstruction at an anatomic $3 \mathrm{D}$ defined point. Even for the planning of orthodontic bimaxillary surgery to define the searched interincisal point for the best position of the maxilla and the mandible, this CranioSphere ${ }^{\circledR}$ Analysis will be a predictable method.

Relating this new anatomic angle to the anatomic morphometric results of the Anthropologist Petrus Camper designated "Campersche Ebene" $1792^{5}$ it could be possible to reconstruct the full occlusal plane. Camper dedicated a variation of an angle of $5-7^{\circ}$ between the Campers plane line (spina nasalis anterior to upper part of the porus acusticus externus) and the occlusal plane line in sagittal direction. Developing this idea, and investigating into further scientific studies, it may be possible to reconstruct the position of the occlusal

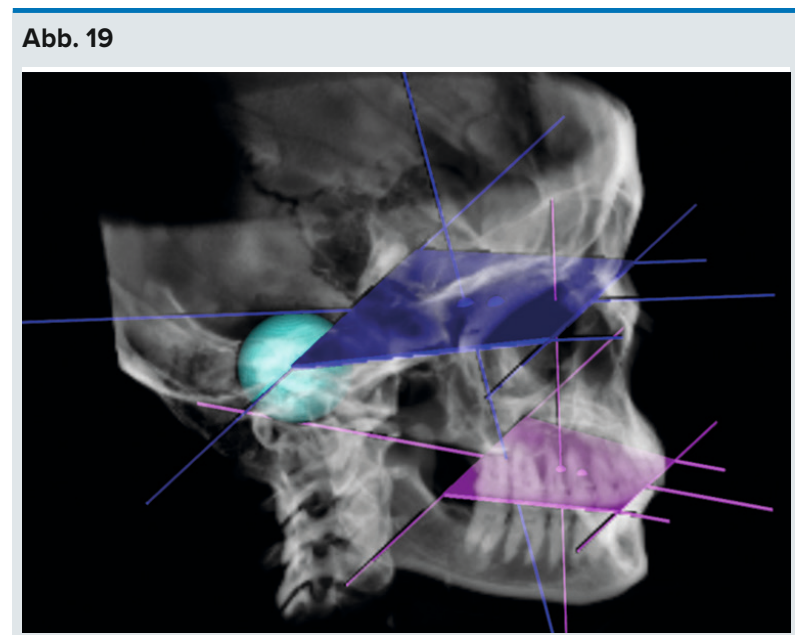

CBCT-View and relation of Cranioplane, Craniosphere and the occlusal plane

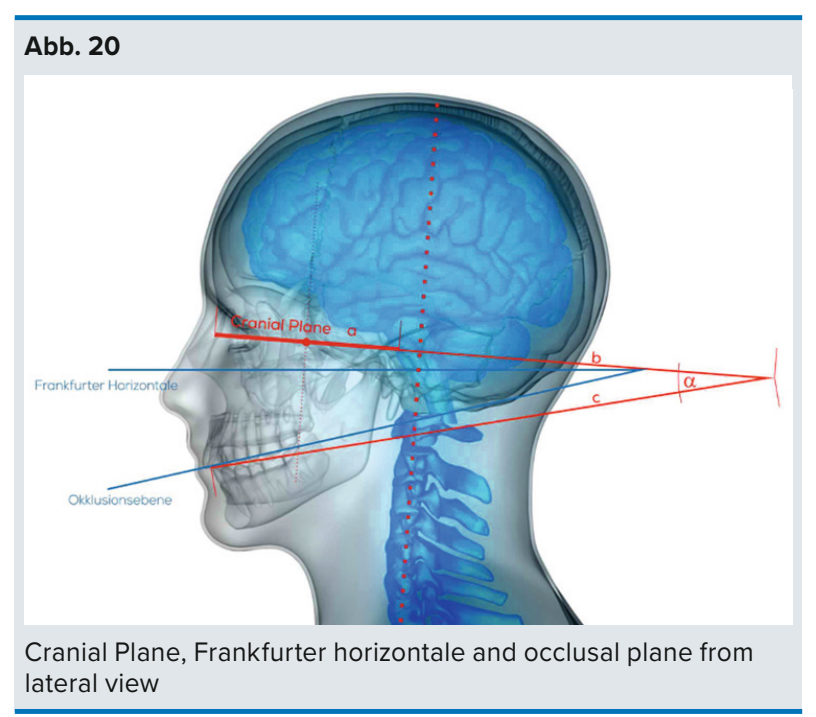


plane in all three dimensions for patients without any teeth. It will be a big step for prosthodontic therapeutic planning of full mouth dentures (Image 21, 22).

\section{Interpretation}

Even in morphometric anthropologist studies or for analysis of facial asymmetries or facial reconstruction in maxillofacial surgery or orthodontics analysis the facial midline plane is the key and anchor-point for all scientific and medical approaches. Thus the determination of this facial midline plane is given such an outstanding necessity however it lacks in the procedure of constitution and reconstruction.

In the past no agreement could be found in which method could be the best and the most precise. Two important facts made it difficult to distinguish the best method. One was the individual failure rate of the re-

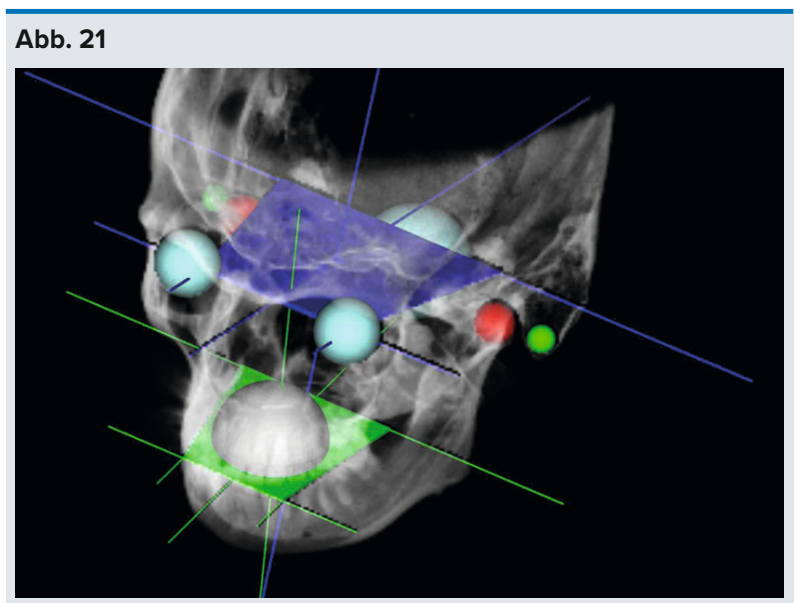

The examined landmarks, points and planes in a 3D skull $x$-ray

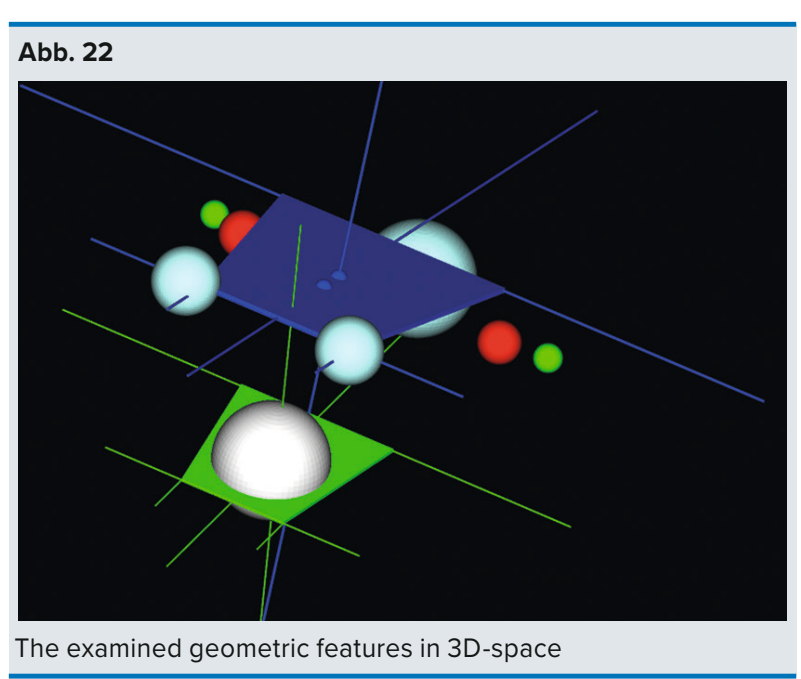

verence point perhaps as a result of asymmetry or inaccuracy itself. The other fact was the lack of reliability to determine and find these anchor points easy and precisely to be elaborated in standard daily analytic use. Former transversal facial asymmetries have been analyzed with frontal anterior-posterior cephalometrics and equivalent photographic images. ${ }^{6,7,8}$

In cephalometric 2D studies, the Ricketts analysis gave the most predictable reliability. Ricketts took only defined cephalometric points for his primary facial axis that originated at the border between the neurocranium and the viscerocranium (Image 23).

Ricketts midline was constructed as the perpendicular $90^{\circ}$ axis proceeding through the sagittal axis defined by the anatomic path of the crista galli. ${ }^{9,10}$ The neurocranium grows before birth without outer sense- or function influences at the amount of nearly $50 \%$ in length. That means there is a lower risk for epigenetic individual growth change, than it is given to the viscerocranium,

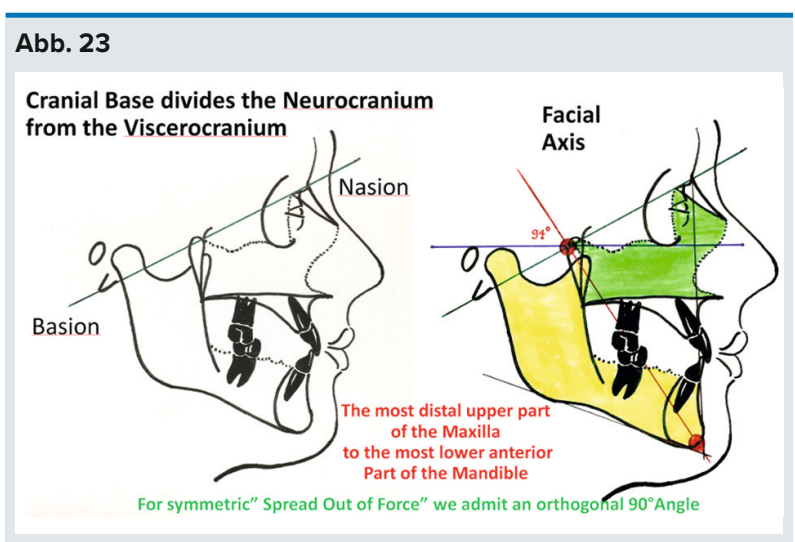

Ricketts based cephalometry with the facial axis lined by the most upper dorsal point of the maxilla to the most lower anterior point of the mandible

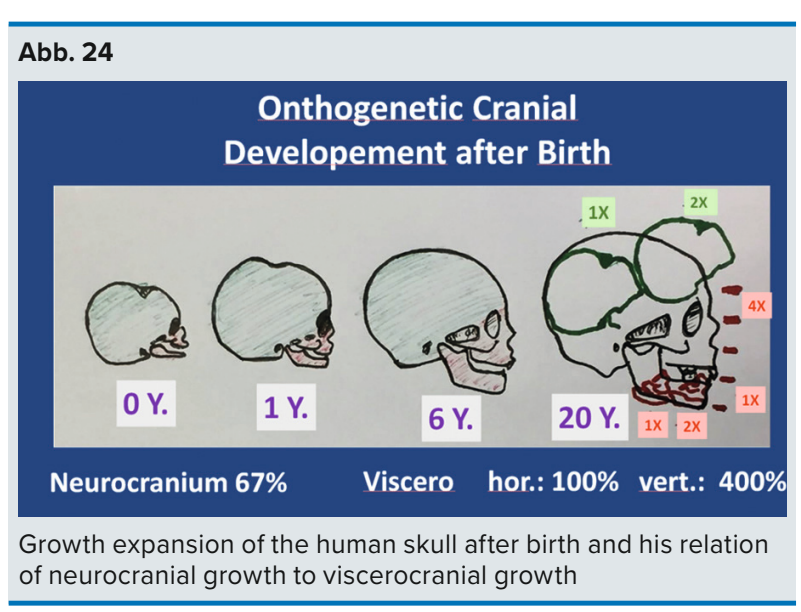


which has between 5 to 7 times more growth change in length and height after birth. So the neurocranium is determined to be the most stable factor in skull measurement and therefore all primary regression points to create a midsagittal plane should only be taken from this area (Image 24). The mistake, most 3D-Cephalometric studies make is that they don't figure out new landmarks, created by new ideas of 3D knowledge and the newly given three dimensional overview of the skull which would be more precise for determination facial asymmetries $^{11}$ than it hardly could be achieved by anaIysis of conventional frontal cephalograms. ${ }^{12,13}$ Mostly they transfer the 2D cephalometric analysis in the world of $3 D$. It is obvious that this procedure will enhance the failure of correct landmark positioning because it will multiply the chance of failure rate for a then assessed analysis point in the 3D environment.

The common three 3D-determinations for the midsagittal plane are cephalometric analysis, morphometric measurements and voxel-based 2D-Analysis. ${ }^{14,15}$ The cephalometric analysis transfers the $2 \mathrm{D}$ experience into the 3D world. They are easy to handle and even can be taken from the combination of lateral and anterior-posterior 2D X-ray. However, their failure rate therefore is very high. Even the fact that no landmark of the lateral cephalometric analysis can be proven in reality because of the enlargement effect of the X-ray radiation, this makes it impossible to ensure real anatomic results. The fact of this is that this mistake is repeated with every landmark point and will be minimized if your point of view is given by angles. So for general orthodontic practitioners the traditional cephalometric analysis can make sense when quoting the outcome of the different angle relations. In the time of 3D the access approach it is not state of the art to revert back to this outdated standard analysis. Therefore new methods and new ideas have to be established.

The morphometric measurements need many real soft tissued points for the analysis and they can define the real midline plane. But as in many cases the number of intact parts of the skull are not sufficient in order to use this method morphometric measurements are not sufficient to find precise and stable points for reconstructive analysis. ${ }^{14}$
The third method is to generate a voxel-based midline as the result in the greatest count of paired voxels on opposing sides of the CT-dataset. The effort to create such software is very high and only to be used for scientific research. There is no comparative useful software on the market. ${ }^{16}$

The battle of the best landmarks has not yet been fought out. So Dobai et al. reassumed, that in literature, there is no consensus about the method to use in order to construct the facial midplane in $3 \mathrm{D} .{ }^{17}$ The most commonly used method is to define three cephalometric landmarks as reference points for the midsagittal plane ${ }^{18,19}$ or by using reference points and planes together. $^{14,17}$

The further away the landmarks are positioned from the neurocranium and from the sagittal center of the cranium the more inaccuracy they will produce. Swennen defined the midline plane with the points Sellanasion-menton, S-N-ME. ${ }^{19}$ As menton or gonion is at the most lower anterior position of the mandible, it is too far away from the solid neurocranial anatomy to produce precise results. Other Authors constructed a line along the crista galli and connected the anterior end, the spina nasalis anterior with midlandmarks of the mandible. ${ }^{20}$ It is obvious that with this method, where all landmarks are placed outside of the neurocranium and having no relation to afferent nerve points, the results could not be sufficient for any precise orthognatic surgery planning.

With the analysis of Cho et al. the approach to a reliable result enhanced. He defined the midsagittal plane with the sella-nasion-basion points, S-N-BA. ${ }^{18}$ The goal of Shin et al. was, to take the closest landmarks to the midsagittal plane and not to reconstruct reverence points out of two landmarks. He chose the N-ANS-PNS combination. ${ }^{15}$ As the Anterior Nasal Spine point is not located close to the neurocranium and even if it can be traumatically injured by a fracture, ${ }^{21,22}$ this definition of the midsagittal plane is not exact enough and quite vulnerable considering the fact, that nasal fracture is one of the most common types of facial fractures. ${ }^{23}$ Thiesen suggested to use additional cranial based landmarks. ${ }^{24}$ 
The hypothesis to stay close to the neurocranial structures seems to be substantiated. However, as Lisboa emphasized, that the orbitale, the most upper and most frontal point of the orbita shows a higher failure rate, ${ }^{25}$ it is due to the fact, that the real position of this point easily can be misinterpreted. So this approach is not dedicated to the definition of Point $A 1$ and $A 2$ of the CranioPlan ${ }^{\circledR}$-Analysis as these points are reproduced very easily and precisely.

One of the latest studies to this field of scientific interest is published by the Hungarian group around Dobai et al. in $2018 .{ }^{17} \mathrm{He}$ assumed that the triangle build up with the landmarks N-ANS-PNS as described by Shin et al ${ }^{15}$ is the most solid point of view for the midsagittal plane. He took this midsagittal plane as reference to construct planes with other landmarks and measured the deviating angle. He also compared two groups, patients with evident transversal asymmetry and patients with an assumed symmetric face. Both groups undergone analysis originating from unpaired landmarks from the suggested midsagittal plane and of the middle points of paired landmarks and then measured the deviation.

The results have been sobering. In the symmetric group only $86 \%$ of the unpaired and only $74 \%$ of the paired group had a deviation of the compared planes under $5^{\circ}$. In the asymmetric group the results even have been worse. In the group with facial asymmetry $84 \%$ of the regression planes generated from unpaired landmarks and $60 \%$ of the planes based on paired points had a deviation less than $5^{\circ}$ from the reference plane degree. ${ }^{17}$ Considering that in a face with a height of $20 \mathrm{~cm}$ a deviation of $2^{\circ}$ will significantly affect a difference of $7 \mathrm{~mm}$ in the periphery it is obvious, that none of the investigated methods are exact enough to deliver highly recommended precise results, for instance for the use of pre-surgical orthognathic surgery analysis.

The best results in the Dobai study ${ }^{17}$ have been reached by comparing planes defined with unpaired landmarks close to neurocranium or with unpaired landmarks located in the neurocranial region. The single acceptable result with paired landmarks had been within the orbitale as reference landmarks. This can be interpreted as proof, that the orientation to neurocranial anatomic structure is the way for better results and to get en- hancement in more reliable preciseness. The authors have already covered vital parts of the ground work und basic research which have been published in several journals in recent years. ${ }^{26,27,28,3,29,1,30}$

As further scientific investigations are necessary because none of the common existing methods show reliable noteworthy results for scientific approach and are not really precise enough as a base for dentofacial and orthognathic surgery, new methods such as described here, CranioPlan ${ }^{\circledR}$ Analysis are strongly required. It is the inner wish of the authors, that the University-Societies will take the opportunity to prove this new idea of dentofacial analysis.

\section{Summary}

CranioPlan ${ }^{\circledR}$ and CranioSphere ${ }^{\circledR}$ is a new method of craniofacial 3D-analysis based on landmarks defined by anatomic points of afferent reception followed by the hypothesis that the afferent senses need to have the maximum calibration for the species to guarantee sufficient orientation in the surrounding environment and as consequence of faunal evolution success. The points of auriculotemporal-, visual- and gravity- sense penetration into the human skull were taken as basic references to define the true origin midsagittal plane which is the key for further anatomic investigations like orthognathic surgery planning and dental mouth reconstruction or even anthropological studies.

Literature reflects the lack of accuracy in the established cranial skull analysis and the lack of comparability between the existing methods. Newer technologies such as MRI and CBCT increase the possibilities for developing and evolving new methods for a sophisticated, scientific analysis. However, there is a crucial need to have a reliable important tool to create sufficient scientific and medical outcomes. This new neuroanatomic landmark based analysis will help to find more reliable and more precise results for any anatomic study and to serve for human health treatment.

The authors are looking forward to this hypothesis being questioned and put to practical use. We hope that many methods and ideas may be derived from this, centered in a new axiom of human symmetry. The author states that there is no conflict of interest. There was no external source of founding. 


\section{Literatur}

1. Hornung F, Polzar G, Weihe S. CranioPlan ${ }^{\circledast}$ - Verfahren zur Bestimmung der cranialen Symmetrieebene. J Compr Dentof Orthod + Orthop (COO) 3-4:30-48; 2016.

2. Polzar G, Hornung F, Weihe S. Cranioplan - Verfahren zur Bestimmung der cranialen Symmetrieebene. KN Kieferorth Nachrich Compendium 2017:22.31; 2017.

3. Polzar G, Süss JT. Überlegungen zur Symmetrie des humanen Schädels. J Compr Dentof Orthod + Orthop (COO) 3-4:26-29; 2016.

4. Polzar G. Alignertherapie in der Kieferorthopädie. 1. Büdingen: Selbstverlag; 2012.

5. Camper P. Über den natürlichen Unterschied der Gesichtszüge in Menschen verschiedener Gegenden und verschiedenen Alters: über das Schöne antiker Bildsäulen und geschnittener Steine; nebst Darstellung einer neuen Art, allerlei Menschenköpfe zu zeichnen. Berlin: Voss; 1972.

6. Choi KY. Analysis of facial asymmetry. Arch Craniofac Surg 16:110; 2015.

7. Aoshima O. Investigation of the facial symmetry of cases with cross bites needing surgical orthodontic treatment using postero-anterior roentgenographic cephalometrics. Nihon Kyosei Shika Gakkai Zasshi 49:256-262; 1990.

8. Haraguchi S, Takada K, Yasuda Y. Facial asymmetry insubjects with skeletal class III deformity. Angle Orthod 72:28-35; 2002.

9. Jacobson A, Jacobson RL. Radiographic cephalometry: from basics to 3-D imaging. Quintessence, New Malden; 2006.

10. Ricketts RM, Bench RW, Gugino CF, Hilgers JJ, Schulhof RJ. Bioprogressive Therapie. 3rd ed. Hüthig; 1995.

11. Bajaj K, Rathee P, Jain P, Panwar VR. Comparison of the reliability of anatomic landmarks based on PA cephalometric radiographs and 3D CT scans in patients with facial asymmetry. Int $J$ Clin Pediatr Dent 4:213-223; 2011.

12. Major PW, Johnson DE, Hesse KL, Glover KE. Landmark identification error in posterior anterior cephalometrics. Angle Orthod 64:447-454; 1994.

13. Sicurezza E, Greco M,Giordano D,Maiorana F,Leonardi R. Accuracy of landmark identification on postero-anterior cephalograms. Prog Orthod 13:132-140; 2012.

14. Damstra J, Fourie Z, De Wit M, Ren Y. A three-dimensional comparison of a morphometric and conventional cephalometric midsagittal planes for craniofacial asymmetry. Clin Oral Investig 16:285-294; 2012.

15. Shin SM, Kim YM, Kim NR, Choi YS, Park SB, Kim YI. Statistical shape analysis-based determination of optimal midsagittalre- ference planefor evaluation offacial asymmetry. Am J Orthod Dentofacial Orthop 150:252-260; 2016.

16. Wong TY, Liu JK, Fang JJ, Wu TC, Tu YH. Use of the matching optimal symmetry plane method in planning surgical correction of facial asymmetry-a preliminary report of 20 patients. J Oral Maxillofac Surg 72(1180):e1-e13;

17. Dobai A, Markella Z, Vízkelety T, Fouquet C, Rosta A, Barabás J. Landmark-based midsagittal plane analysis in patients with facial symmetry and asymmetry based on CBCT analysis tomography. J Orofac Orthop 79:371-379; 2018.

18. Cho JH, Moon JY. Comparison of midsagittal reference plane in PA cephalogram and 3D CT. Korean J Orthod 40:6-15; 2010.

19. Swennen GRJ. Three-dimensional cephalometry: a color atlas and manual. Berlin: Springer; 2010.

20. Harsh M, Gowdra S, Maurya RK. Assessment of facial asymmetry in various malocclusion: a comparative analysis. J Indian Orthod Soc 48:534-545; 2014

21. Escada P, Penha RS. Fracture of the anterior nasal spine. Rhinology 37:40-42; 1999 .

22. Raggio BS,Graham HD. Fracture of the anterior nasal spine: a systematic review [Internet]. J Oral Maxillofac Surg Med Pathol; 2017. Available from: https://doi. org/10.1016/j.ajoms.2017.09.008

23. Bajwa RA, Mehmood F, Jalil S. Frequency and etiology of different types of nasal bones fracture reporting at a tertiary care centre, Lahore, Pakistan. J. Med Sci 6:703-709; 2012.

24. Thiesen $G$. Determining the midsagittal reference plane for evaluating facial asymmetries. Am J Orthod Dentofacial Orthop 150:908-909; 2016.

25. Lisboa Cde O, Masterson D, da Motta AF, Motta AT. Reliability and reproducibility of three-dimensional cephalometric landmarks using СВСТ: a systematic review. J Appl Oral Sci 23:112119; 2015.

26. Polzar G, Hornung F. DVT - Praktischer Nutzen in der Kieferorthopädie. J Compr Dentof Orthod + Orthop (COO) 3-4:88-99; 2013.

27. Polzar G, Hornung F. Digitale KFO-Therapie auf Basis von 3DVoxeldatensätzen aus dem DVT. J Compr Dentof Orthod + Orthop (COO) 3-4:40-49; 2015.

28. Polzar G, Hornung F. Volldigitale Kieferorthopädie - eine Geschichte. J Compr Dentof Orthod + Orthop (COO) 3-4:32-39; 2015.

29. Polzar G, Weber D. MRT-Diagnostik in der Kieferorthopädie. J Compr Dentof Orthod + Orthop (COO) 3-4:13-33; 2008.

30. Polzar G, Herberg M. Mythos DVT. J Compr Dentof Orthod + Orthop (COO) 3-4:24-30; 2019 